\title{
Interlaminar Fracture Toughness Evaluation in Glass/Epoxy Composites Using Acoustic Emission and Finite Element Methods
}

\section{Milad Saeedifar}

Mohamad Fotouhi 1

Mehdi Ahmadi Najafabadi 1,*

Phone (+98 21) 64543431

Emailmilad.saeedifar@aut.ac.ir

Emailahmadin@aut.ac.ir

Hossein Hosseini Toudeshky 2

1 Non-destructive Testing Lab, Department of Mechanical Engineering, Amirkabir University of Technology, $424 \mathrm{Hafez}$ Ave, 15914 Tehran, Iran

2 Department of Aerospace Engineering, Amirkabir University of Technology, 424 Hafez Ave, 15914 Tehran, Iran

\section{Abstract}

Delamination is one of the most common modes of failure in laminated composites and it leads to the loss of structural strength and stiffness. In this paper, mode I, mode II, and mixed of these pure modes were investigated using mechanical data, Finite Element Method (FEM) and Acoustic Emission (AE) signals. Experimental data were obtained from in situ monitoring of glass/epoxy laminated composites with different lay-ups when subjected to different modes of failure. The main objective was to investigate the behavior of delamination propagation and to evaluate the critical value of the 
strain energy which is required for onset of the delamination $\left(G_{\mathrm{C}}\right)$. For the identification of interlaminar fracture toughness of the specimens, four methods were used: (a) ASTM standard methods, (b) FEM analysis, (c) AE method, and (d) sentry function method which is a function of mechanical and AE behaviors of the specimens. The results showed that the $G_{\mathrm{C}}$ values obtained by the sentry function method and FEM analysis were in a close agreement with the results of nonlinearity methods which is recommended in the ASTM standards. It was also found that the specimens under different loading conditions and various lay-up have different $G_{\mathrm{C}}$ values. These differences are related to different stress components distribution in the specimens which induce various damage mechanisms. Accordingly, stress components distribution obtained from FEM analyses were in agreement with SEM observations of the damaged surfaces of the specimens.

\section{Keywords}

acoustic emission

delamination

FEM analysis

interlaminar fracture toughness

sentry function

\section{Introduction}

Glass fiber reinforced plastics (GFRP) are being increasingly utilized in engineering applications due to their high specific strength and stiffness. Delamination in GFRP has been a subject of intensive research since many years. This failure mechanism can be caused by improper manufacturing, stresses between the layers of the composite, transversal load, and impact. In many real conditions, delamination occurs mainly in mode I, mode II, and the combination of these pure modes. Its effect on the structure may include a dramatic loss of residual strength and stiffness (Ref 1). Understanding the delamination initiation and propagation behavior is useful to produce structures with higher strength against crack growth ( Ref 2). 
Delamination is an insidious failure mode that is frequently present within the composite and it may easily escape detection (Ref 3$)$. Passive methods, such as AE, may improve the reliability and confidence of delamination detection (Ref 4-8). AE technique uses a piezoelectric transducer to receive the first signs of damage in a structure. AE signal is a transient wave originated by the damage mechanisms such as matrix cracking, fiber failure, debonding of the matrix from fibers, etc. This technique is an appropriate tool to detect in situ information about the damages that occur during initiation and propagation of delamination (Ref 8-10).

A huge amount of literature has been published on mode I delamination and investigation of this damage using AE monitoring (Ref 11-16). Benmedakhene et al. (Ref 14) evaluate initiation and propagation of delamination in laminated composites under static and dynamic mode I loading using AE. They investigate damage mechanisms and AE behavior of the specimens under different loading rate. Refahi et al. (Ref 15,16$)$ study delamination in glass/polyester composites under mode I loading condition using AE. They determine the initiation of delamination and ranges of the parameters of AE signals of the damage mechanisms that occur during delamination. Arumugam et al. (Ref 17) investigate delamination and the damage mechanisms in glass/epoxy composite specimens under mode I loading using AE and Fast Fourier Transform (FFT) analysis. Taghizadeh et al. (Ref 18) classify the damage mechanisms during mode I delamination in polypropylene/epoxy composites using AE and Principal Component Analysis (PCA) methods.

On the other hand, little work has been done on the behavior of delamination in laminated composites using AE method when they are subjected to different loading conditions (i.e. mode II and mixed-mode types). This is due to experimental difficulties related to unstable crack growth and crack tip closure during delamination propagation under these modes. These factors prevent a rigorous measurement of mode II and mixed-mode interlaminar fracture toughness. Pashmforoush et al. (Ref 19) investigate damage mechanisms in glass/epoxy composite under three point bending loading using $\mathrm{AE}$ and k-means genetic algorithm. The results revealed that there are three clusters with 
separate frequency ranges, each one representing a distinct damage mechanism. The obtained results showed good performance of the methods in the damage characterization of composite materials.

Yousefi et al. (Ref 20) evaluate delamination in laminated composites under mode II loading using AE and wavelet-based signal processing.

The aim of this paper is to enhance some applicable and sensitive approaches, based on AE and fracture mechanics, to characterize delamination in glass/epoxy composites under mode I, II, and mixed of these pure modes. In this paper, the behavior of delamination and the critical energy which is required for onset of this defect were studied using mechanical experimental data, FEM analysis (J-integral), AE method, and the combination of mechanical and AE experimental data. The experimental data were obtained from the specimens when subjected to mode I, II, and mixed-mode I and II delamination tests. At first, the mechanical data were used to study the initiation and propagation behavior of delamination in the specimens with various lay -ups under different loading conditions. After that, critical interlaminar fracture energy of the specimens was evaluated using the introduced methods. It was found that the sentry function and FEM approaches provide the lower bound of the interlaminar fracture toughness values. There was a good agreement between these results and the results of NL method. However, the results obtained using the VIS and 5\%/max methods represent the upper bound values.

\section{Experimental Procedures}

\section{Materials and Specimens Preparation}

The experimental work was carried out on the epoxy resin (SR1500 made by Sicomin $^{\circledR}$ ) reinforced by the E-glass unidirectional (AT 390 UD 038 made by COLAN $^{\circledR}$ ) and woven fibers (COLAN AF 207 made by COLAN ${ }^{\circledR}$ ) with the density of $1.46 \mathrm{~g} / \mathrm{cm}^{3}, 390 \mathrm{~g} / \mathrm{m}^{2}$, and $300 \mathrm{~g} / \mathrm{m}^{2}$, respectively. The specimens used for this study are specified in Table 1. The laminates were prepared by hand lay-up method. The initial crack was formed by inserting a Teflon film with a thickness of $20 \mu \mathrm{m}$ at midplane of laminated composite during molding. The laminated composite 
specimens consisted of a rectangular shape and uniform thickness (see Fig. 1).

Table 1

Specification of the specimens

\begin{tabular}{|l|l|l|}
\hline & \multicolumn{2}{|l|}{ Specimens lay-up } \\
\hline & $\begin{array}{l}\text { Unidirectional } \\
\left(\mathbf{0}^{\circ}\right)\end{array}$ & $\begin{array}{l}\text { Woven }\left(\mathbf{0}^{\circ}-\right. \\
\left.\mathbf{9 0}^{\circ}\right)\end{array}$ \\
\hline Mode I & $\mathrm{U} 1$ & $\mathrm{~W} 1$ \\
\hline $\begin{array}{l}\text { Mixed-Mode I and II }\left(G_{\mathrm{II}} /\right. \\
\left.\left(G_{\mathrm{I}}+G_{\mathrm{II}}\right)=30 \%\right)\end{array}$ & $\mathrm{U} 2$ & $\mathrm{~W} 2$ \\
\hline Mode II & $\mathrm{U} 3$ & $\mathrm{~W} 3$ \\
\hline
\end{tabular}

Fig. 1

Specimens geometry and dimensions

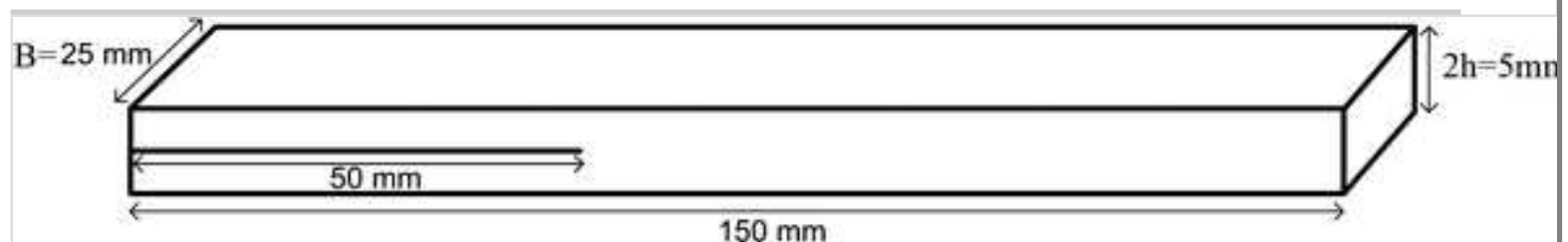

\section{Test Procedures}

DCB, MMB, and ENF test apparatus shown in Fig. 2 were used to apply the load to the laminated specimens. In DCB setup, an upward force is applied to split end of the laminate to create Mode I. Whereas in ENF setup, a downward load is applied to the specimen center to create Mode II. MMB is the combination of DCB and ENF. The length of the MMB lever arm can be changed to vary the $G_{\mathrm{II}} / G_{\mathrm{T}}$ modal ratio values. In this study, $G_{\mathrm{II}} / G_{\mathrm{T}}=30 \%$ modal ratio value was studied. The tests were carried out at a temperature of $24{ }^{\circ} \mathrm{C}$ and at the constant displacement rate of $2 \mathrm{~mm} / \mathrm{min}$. The load and displacement were continuously measured and the crack length was visually recorded using a digital camera. The tests were iterated three times for each type of the specimen in constant loading conditions.

\section{Fig. 2}


Experimental setups for loading and the AE sensors; (a) mode I, (b) mixed-mode I and II, and (c) mode II
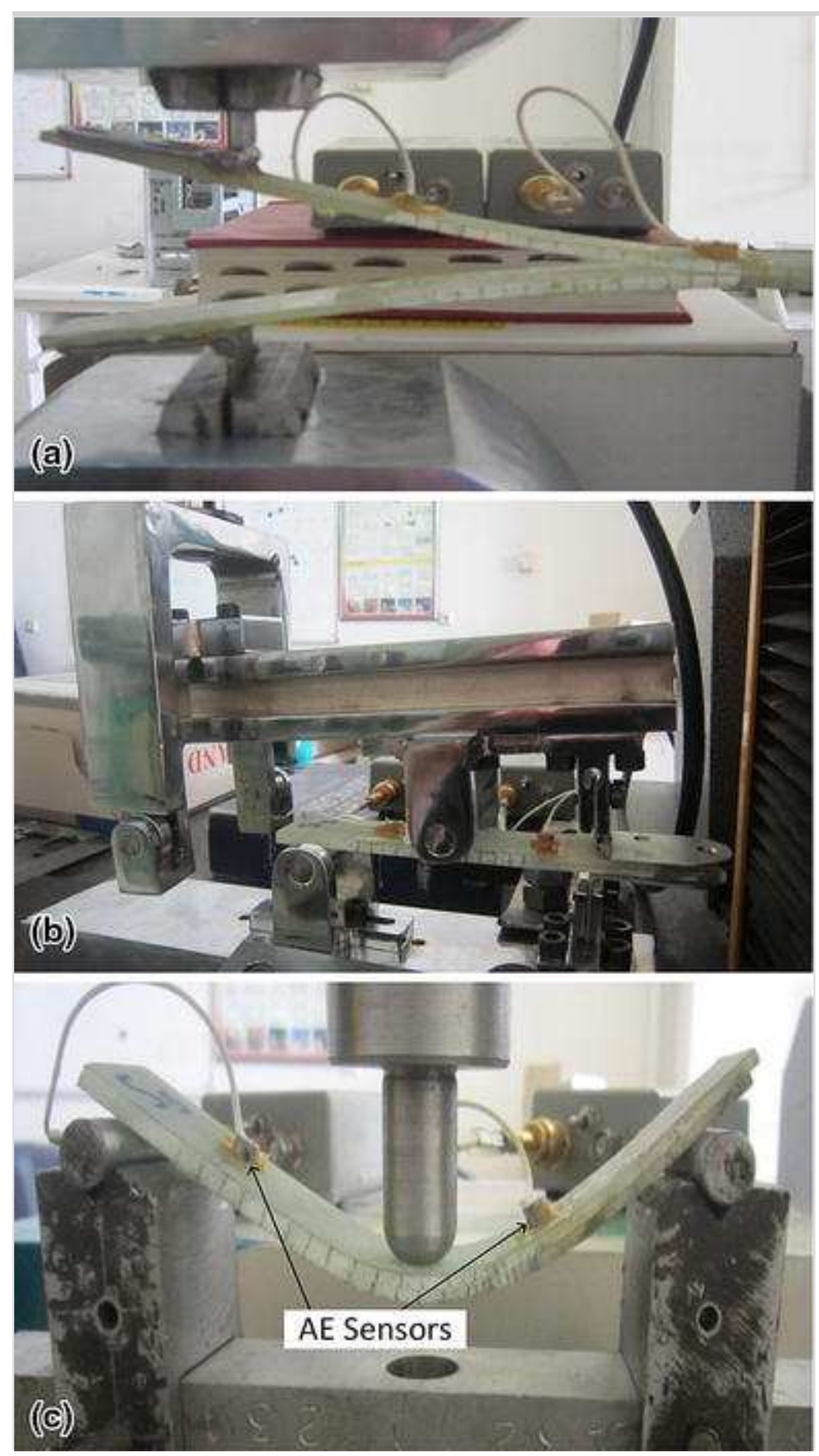

\section{Testing Machine}

A properly calibrated tensile test machine (HIWA) in the speed range from 0.5 to $500 \mathrm{~mm} / \mathrm{min}$ was used in a displacement control mode with a constant crosshead speed. All the specimens were loaded with constant $2 \mathrm{~mm} / \mathrm{min}$ crosshead rate. 


\section{AE Device}

AE events were recorded using AE software (AEWin) and a data acquisition system Physical Acoustics Corporation (PAC) PCI-2 with a maximum sampling rate of $40 \mathrm{MHz}$. PICO which is a broadband, resonant-type, single-crystal piezoelectric transducer from PAC, was used as the AE sensors. The sensors have a resonance frequency of $513.28 \mathrm{kHz}$ and an optimum operating range of $100-750 \mathrm{kHz}$. In order to provide good acoustic coupling between the specimen and the sensors, surfaces of the sensors were covered with grease. The AE signals were detected by the sensors and enhanced by a 2/4/6-AST preamplifier. The gain selector of the preamplifier was set to $40 \mathrm{~dB}$. The test sampling rate was $1 \mathrm{MHz}$ with 16 bits of resolution between 10 and $100 \mathrm{~dB}$. Prior to the damage check, the data acquisition system was calibrated for each kind of specimen, according to a pencil lead break procedure. The lead breakage operation was repeated several times and at different locations between the sensors. After the calibration step, AE signals were captured during mechanical testing using the sensors.

\section{Fracture Toughness}

\section{Energy Release Rate}

In a body with linear elastic behavior, strain energy release rate $(G)$ is expressed by Eq 1:

$$
G=-\frac{d U}{B d a}
$$

where $a, B$, and $U$ are crack length, width, and total elastic strain energy of the test specimens, respectively (Ref 21 ).

Energy release rate for mode I (DCB), mode II (ENF), and mixed-mode (MMB) tests are as follows (Ref 22):

$$
\begin{gathered}
G_{\mathrm{I}}=\frac{12 P^{2} a^{2}}{E B^{2} h^{3}}, \\
G_{\mathrm{II}}=\frac{9 P^{2} a^{2}}{16 E B^{2} h^{3}},
\end{gathered}
$$




$$
\begin{aligned}
G_{\mathrm{I}}=\frac{12 P_{1}^{2} a^{2}}{E B^{2} h^{3}}, \quad G_{\mathrm{II}} & =\frac{9 P_{2}^{2} a^{2}}{16 E B^{2} h^{3}}, \quad \text { and } \quad G_{\text {mixed - mode }}= \\
P_{1} & =\left(\frac{3 C-L}{4 L}\right) P, \quad P_{2}=\left(\frac{C+L}{L}\right) P, \\
\frac{G_{\mathrm{I}}}{G_{\mathrm{II}}} & =\frac{4}{3}\left(\frac{3 C-L}{C+L}\right)^{2} ; \quad C \geq \frac{L}{3}, \\
\frac{G_{\mathrm{II}}}{G} & =\frac{G_{\mathrm{II}}}{G_{\mathrm{I}}+G_{\mathrm{II}}},
\end{aligned}
$$

where $P, P_{1}$, and $P_{2}$ are the applied loads in different loading conditions. $a, B, h$, and $E$ are the delamination length, width of the specimens, half of the specimens thickness and elastic modulus, respectively. $L$ and $C$ are half of the specimen length and length of the mixed-mode fixture lever arm. The dimensions, boundary conditions, and loading conditions of the specimens are shown in Fig. 3.

\section{Fig. 3}

The dimensions, boundary conditions, and loading conditions of the specimen configurations 


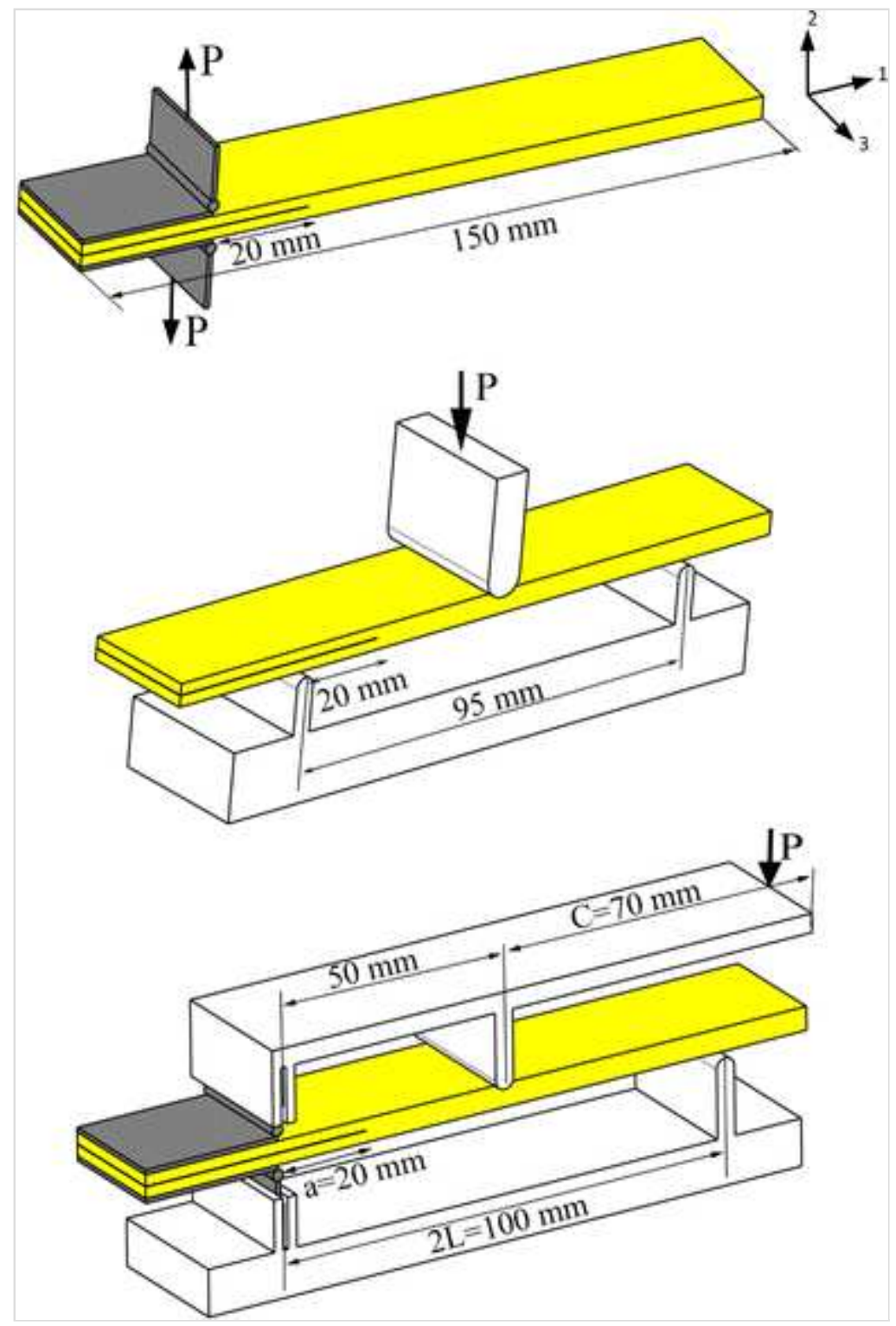

\section{J-Integral}

The energy release rate $(G)$ is used in materials with linear elastic behavior. The J-integral is a fracture characterizing parameter for nonlinear materials. The J-integral is a path-independent contour integral which is used to investigate the cracks in a nonlinear elastic body that contains a pre-crack. Considering an arbitrary counterclockwise path $(\Gamma)$ around the tip of a crack, as it is shown in Fig. 4, the J-integral is given by Eq 5 (Ref 23$)$ :

$$
J=\int_{\Gamma}\left(w d y-T_{i} \frac{\partial u_{i}}{\partial x} d s\right)
$$


where, $w$ strain energy density, $T_{i}$ components of the traction vector, $u_{i}$ displacement vector components, $d s$ length increment along the contour $\Gamma$. In the material with linear elastic behavior, the J-integral and $\mathrm{G}$ are equivalent and could be used interchangeably.

Fig. 4

An arbitrary path around the crack tip for evaluation the J-integral

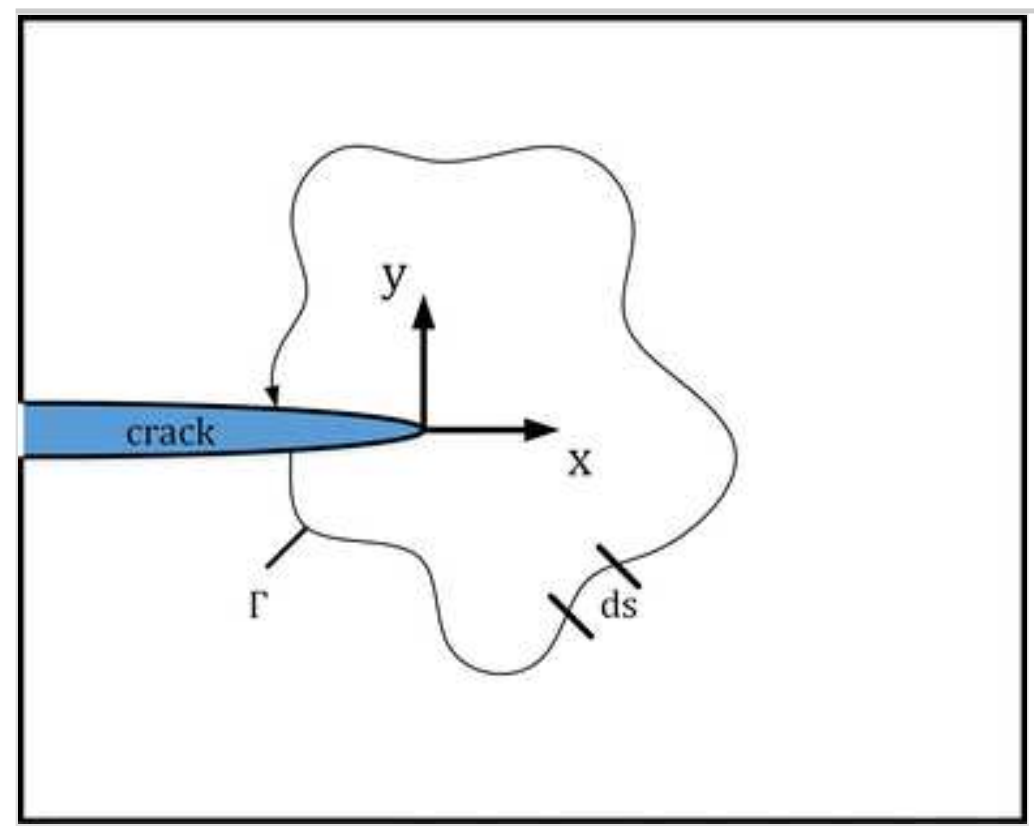

\section{Results and Discussion}

\section{Delamination Behavior}

The initiation and propagation of delamination and its potential interaction with other modes of failure are related to the crack tip conditions. Different loading conditions and lay-ups are the main reason for diversity of the crack tip conditions (Ref 24).

Normal stress in the crack tip is the cause of mode I delamination, when two layers are pulled apart, whereas shear stresses near the crack tip promote mode II (shear) propagation when sliding is observed (Ref 23).

Figure 5 to 7 show load-displacement and crack growth-displacement curves for the DCB, MMB, and ENF specimens. Similar to Fig. 8, the load-displacement diagrams of the specimens can be divided into three regions: (a) from the beginning to the nonlinearity point, (b) from the 
nonlinearity point to the maximum load, and (c) from the maximum load to end of the test.

\section{Fig. 5}

Load-displacement and crack length-displacement diagrams for specimens U1 and W1 (mode I)

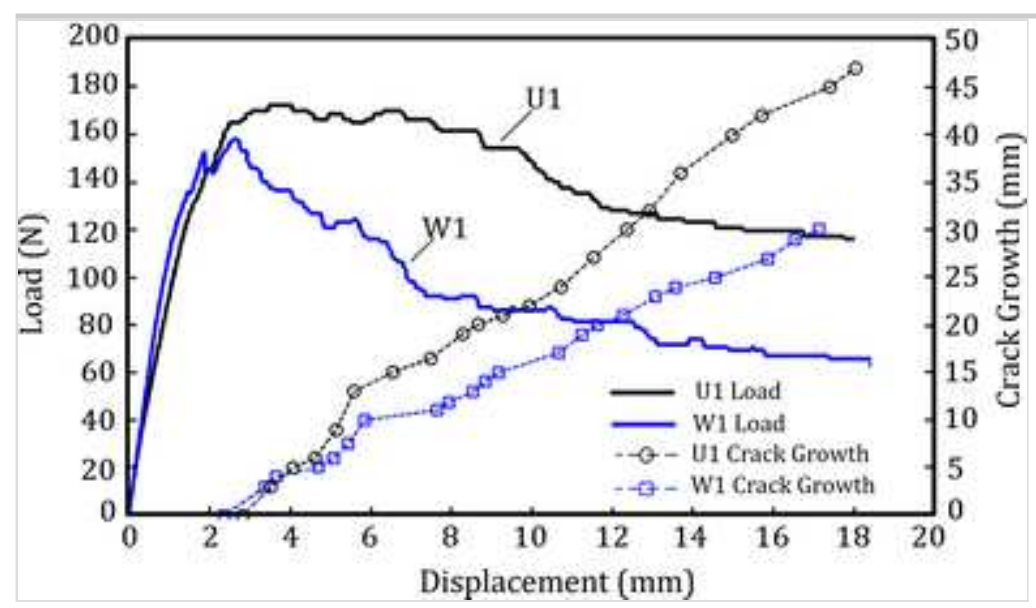

Fig. 6

Load-displacement and crack length-displacement diagrams for specimens $\mathrm{U} 2$ and $\mathrm{W} 2$ (mixed-mode with $G_{\mathrm{II}} / G_{\mathrm{T}}=30 \%$ )

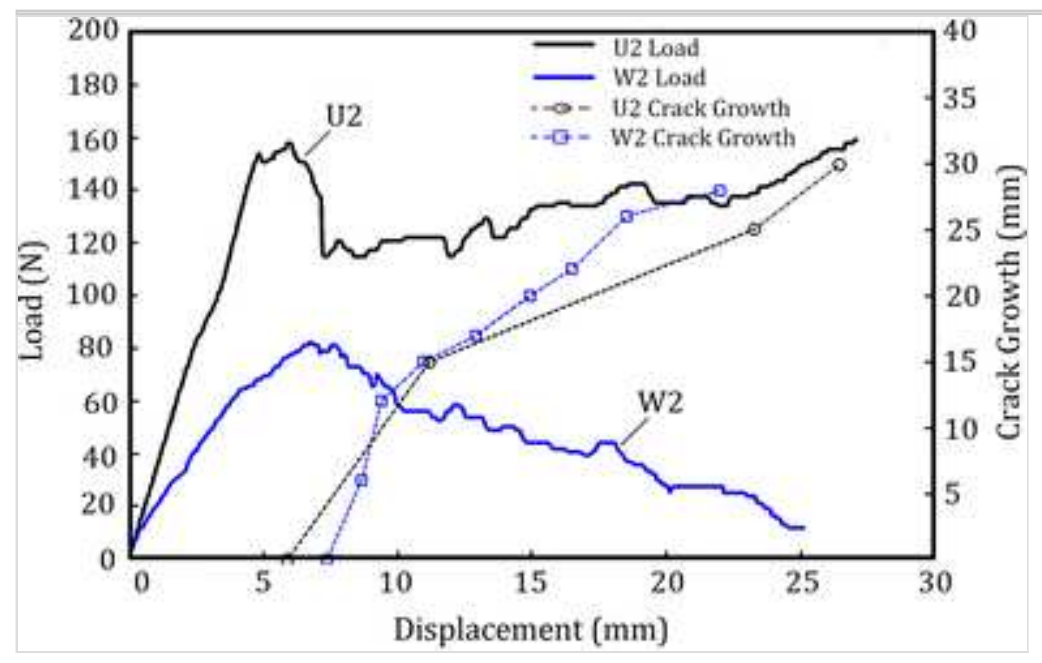

Fig. 7

Load-displacement and crack length-displacement diagrams for specimens U3 and W3 (mode II)

http://eproofing.springer.com/journals/printpage.php?token=F0uNpJyzVSkLfuwMLz... 11/5/2014 


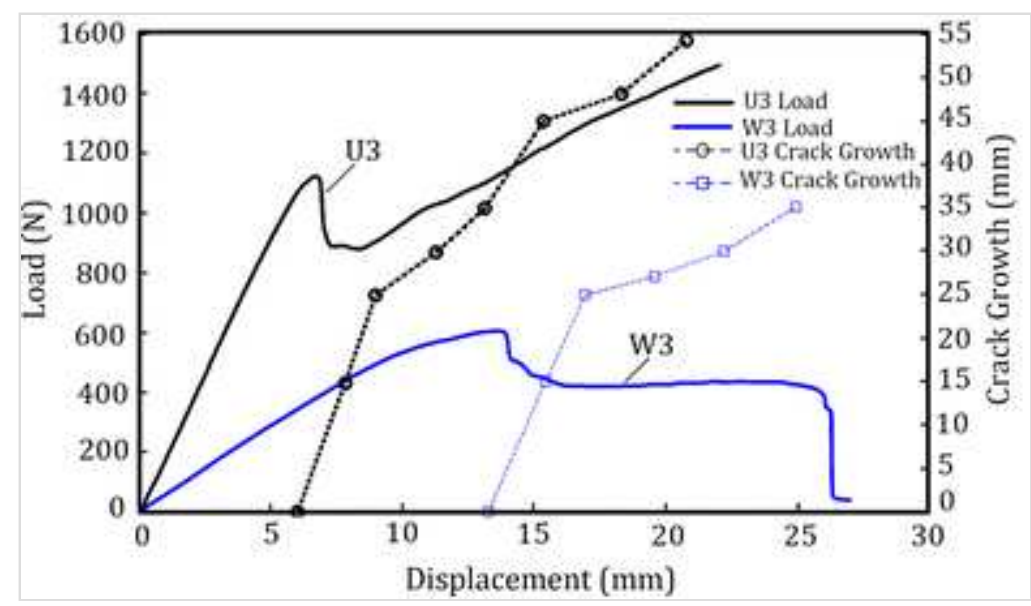

Fig. 8

Three regions of the load-displacement curve of specimen W3

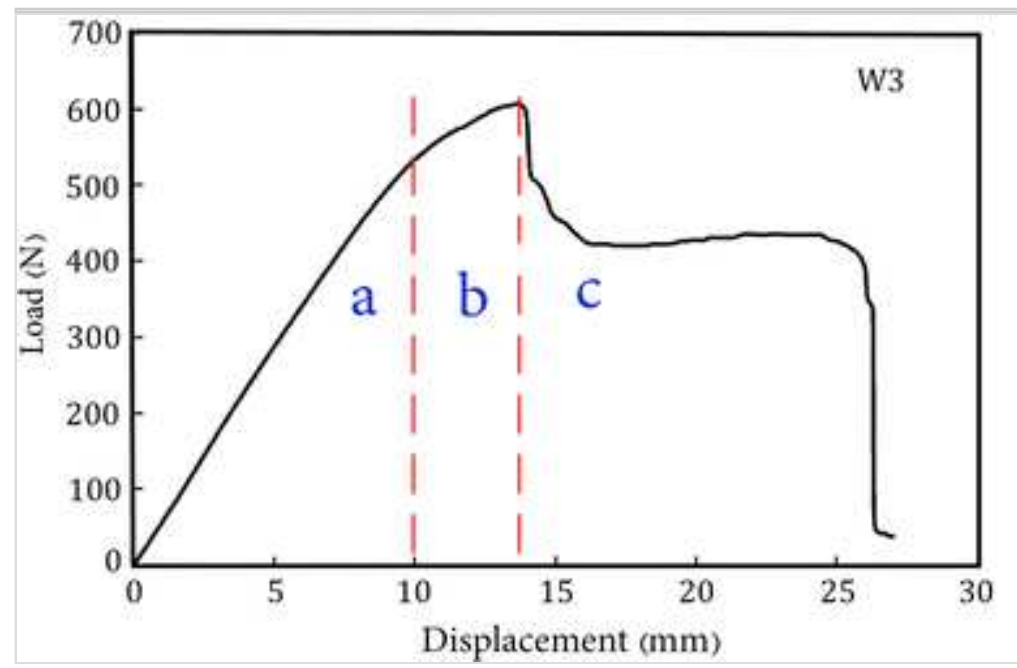

As can be seen from Fig. 8, in region (a), by increasing load, the stored strain energy in the specimens is accumulated, but it does not reach to the critical value. Therefore, the delamination does not initiate. In region (b), the slope of the load-displacement diagram decreases. At the beginning of this region, the stored strain energy in the specimens reaches to the critical value and delamination initiates, but local strain hardening phenomenon arrests the crack growth (Ref 25). In region (c), the delamination growth usually has unstable behavior. As is shown in Fig. 8 the applied load causes the large deflection of specimen W3, which results to the rupture of the specimen and there is a sudden drop of the load at displacement $25 \mathrm{~mm}$.

Referring to the crack length diagrams, the comparison of Fig. 5 to 7 shows that the specimens U1 and W1 have steady state crack growth 
but crack growth behavior of the MMB and ENF specimens change during the tests. In the unidirectional specimens under different loading condition, due to fiber bridging during the delamination process, the load decreases slower than in the woven specimens and residual strength of these specimens are higher than in woven specimens.

\section{Critical Strain Energy Measurement}

A delamination crack will initiate when the available energy release rate $(G)$ is equal or greater than a critical value $\left(G_{\mathrm{C}}\right)$ (Ref 16). This quantity is considered to be a material characteristic that represents the interlaminar fracture toughness of the laminated composites. As $G$ reaches to critical value the crack initiates. Determination of $G_{\mathrm{C}}$ will help for better understanding of the damage tolerances and durability analyses of laminated composites.

$G_{\mathrm{C}}$ can be evaluated by different procedures. In this section, determination procedures are based on the mechanical information, FEM analysis, the AE information, and the combination of mechanical and AE methods. Different procedures for evaluation of critical strain energy are presented in the following:

\section{ASTM Standards}

For evaluation of $G_{\mathrm{C}}$, critical load $\left(P_{\mathrm{C}}\right)$ must first be determined. For determination of $P_{\mathrm{C}}$, the following procedures are presented in ASTM D5528 and ASTM D6671 standards (Ref 21, 22): (a) Nonlinearity in the load-displacement diagram (NL), (b) Visual Inspection System (VIS), and (c) The compliance increase (5\% max). Figure 9 shows values of $P_{\mathrm{C}}$ which are obtained from the above methods for specimen W3.

Fig. 9

Critical load $\left(P_{\mathrm{C}}\right)$ values obtained from ASTM standard methods for specimen $\mathrm{W} 3$ 


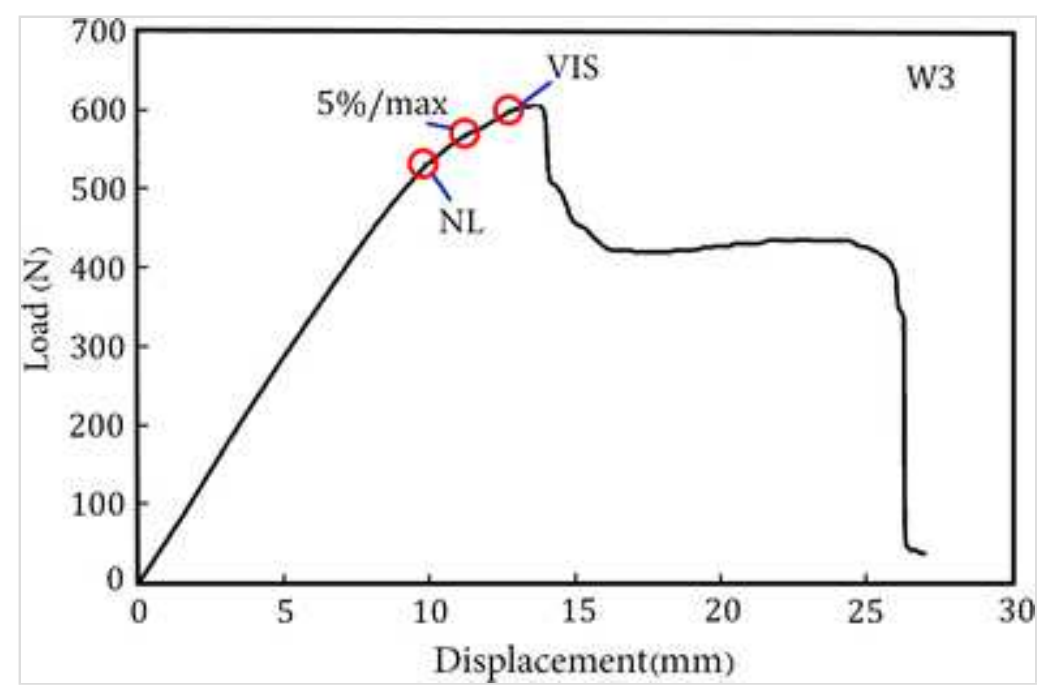

Table 2 shows values of fracture toughness of the specimens obtained from three methods introduced in the ASTM D5528 and ASTM D6771 standards.

Table 2

The $G_{\mathrm{C}}$ values obtained from ASTM standard methods for the specimens

\begin{tabular}{|l|l|l|l|}
\hline \multirow{2}{*}{ Specimens } & \multicolumn{2}{|l|}{$\boldsymbol{G}_{\mathbf{C}}\left(\mathbf{k J} / \mathbf{m}^{2}\right)$} & \\
\hline U1 & NL & $\mathbf{5 \%} / \mathbf{m a x}$ & VIS \\
\hline W1 & 0.63 & 0.96 & 1.07 \\
\hline U2 & 0.453 & 0.59 & 0.66 \\
\hline W2 & 0.24 & 0.72 & 0.79 \\
\hline U3 & 0.107 & 0.148 & 0.159 \\
\hline W3 & 1.976 & 2.10 & 2.16 \\
\hline & 0.37 & 0.43 & 0.47 \\
\hline
\end{tabular}

\section{Finite Element Modeling}

In this section, energy release rate is evaluated using FEM modeling ( $\mathrm{J}$ integral concept). The material properties of the specimens are listed in Table 3. E1 and E2, which have major effect on the FEM results, were obtained using the tensile tests. By knowing the characteristics of the fiber and matrix and also knowing the percentage of the fiber 
contribution in the specimens, the other parameters were obtained from micromechanics principles of composite materials.

Table 3

The material properties of the specimens

\begin{tabular}{|l|l|l|l|l|l|l|l|l|}
\hline Parameters & $\begin{array}{l}\mathbf{E}_{11} \\
(\mathbf{M P a})\end{array}$ & $\begin{array}{l}\mathbf{E}_{\mathbf{2 2}} \\
\mathbf{( M P a})\end{array}$ & $\begin{array}{l}\mathbf{E}_{3 \mathbf{3 3}} \\
\mathbf{( M P a})\end{array}$ & $\mathbf{v}_{\mathbf{1 2}}$ & $\mathbf{v}_{\mathbf{1 3}}$ & $\mathbf{v}_{2 \mathbf{2}}$ & $\begin{array}{l}\mathbf{G}_{\mathbf{1 2}} \\
\mathbf{( M P a})\end{array}$ & $\begin{array}{l}\mathbf{G}_{13} \\
(\mathbf{M P}\end{array}$ \\
\hline Unidirectional & 13,500 & 3200 & 4500 & 0.26 & 0.21 & 0.32 & 2100 & 2700 \\
\hline Woven & 17,500 & 4100 & 15,300 & 0.22 & 0.19 & .25 & 2900 & 3500 \\
\hline
\end{tabular}

Figure 10(a) illustrates the discretized FE model. For these analyses, 2D, plane Strain, continuum (solid) elements with 4-node, and reduced integration formulation (CPE4R elements) are used. Mesh effect was investigated and the large side of the elements in the crack tip applied to be $0.125 \mathrm{~mm}$. Type of the elements in the square region around the crack tip is unstructured and the other are structured elements. The number of the structural elements used through the laminate thickness is 50. Total number of the elements that used for discretization of the model is 35,000 . The critical loads which were obtained by the nonlinearity (NL) method were used as inputs for the FEM analyses. Among the three methods which represented in ASTM D5528 and D6671, the NL method is recommended by the standards (Ref 21, 22). Figure 11 shows distribution of the Von Mises stress in the crack tip of the specimens after loading.

Fig. 10

Schematic of (a) the discretized FE model and (b) some of the contours 


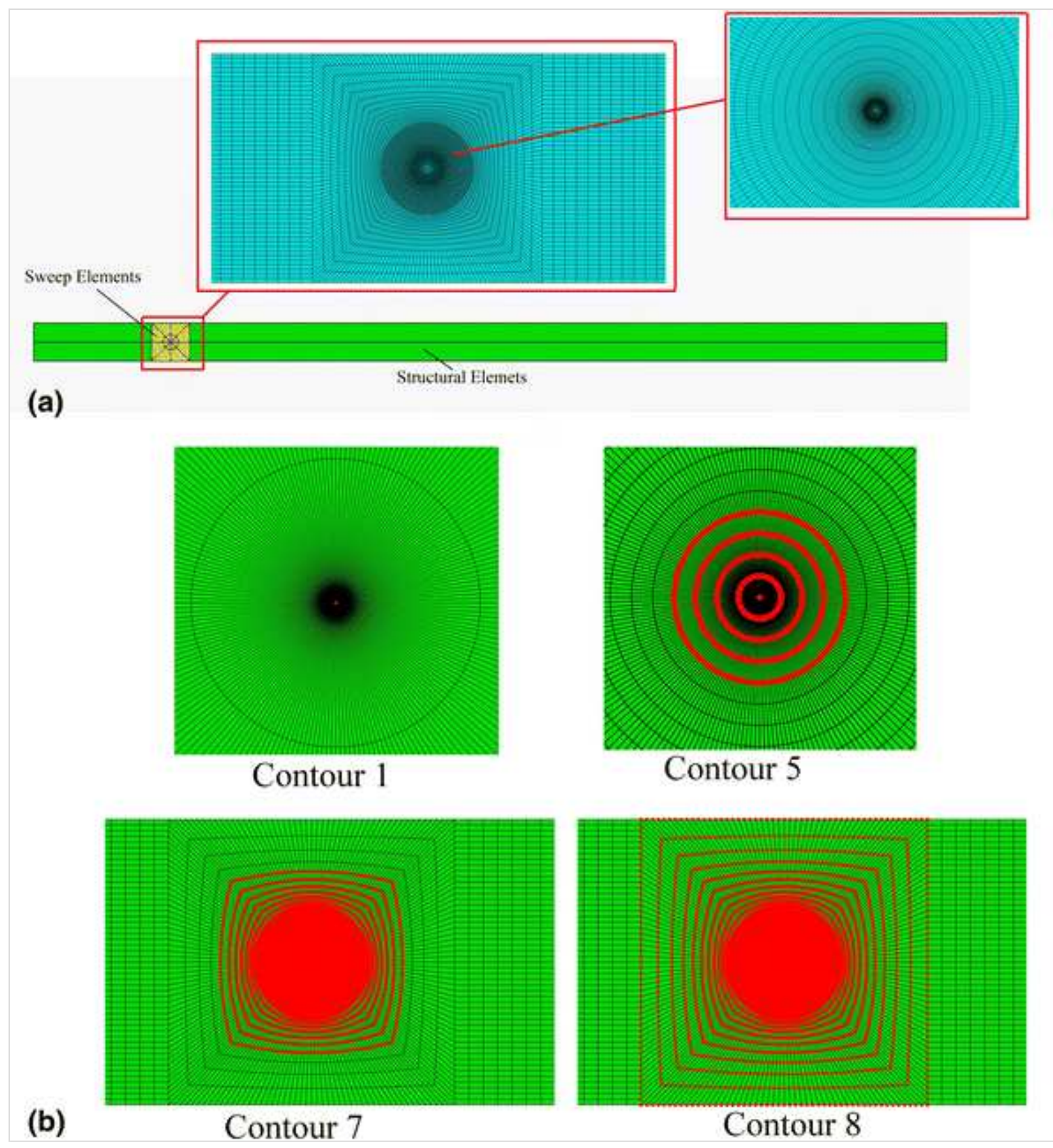

Fig. 11

Von Mises stress distribution in the specimens under: (a) mode I, (b) mixed-mode I and II, and (c) mode II loading conditions

http://eproofing.springer.com/journals/printpage.php?token=F0uNpJyzVSkLfuwMLz... 11/5/2014 

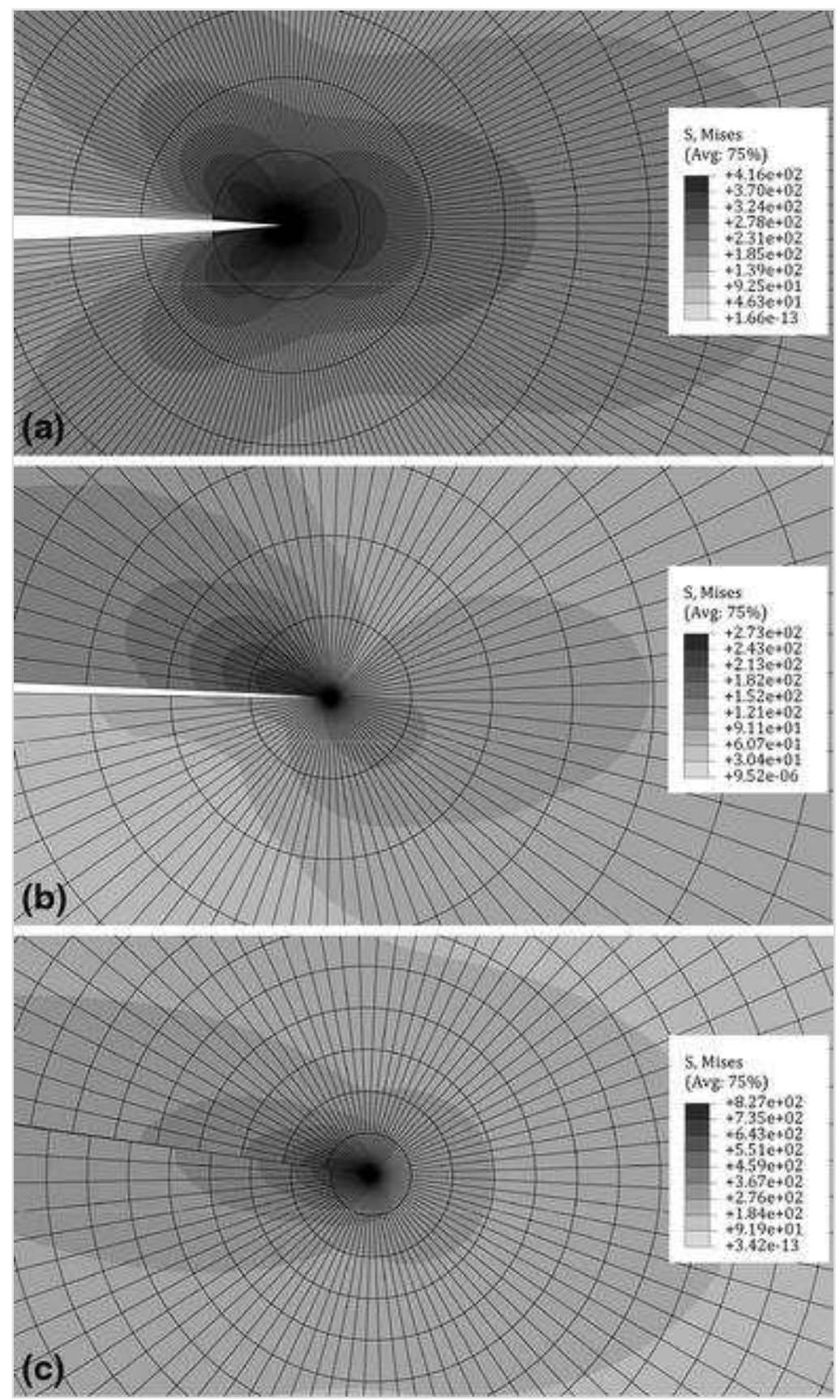

In these analyses, material behavior is considered linear elastic. This assumption is consistent with ASTM D5528 and ASTM D6671 standards (Ref 21, 22). The values of J-integral must be independent from the contours path. Eight contours are considered to calculate the Jintegral and to investigate path-independence of the J-integral values. The results illustrated that the J-integral values obtained from contours 2 through 8 is the same. The aim of selecting 8 contours is to cover the area from the crack tip domain to the domains that are far from the crack tip. The first selected contour consists of only the node at the crack tip while the 8th contour consists of the elements at the yellow square domain around the crack tip (12,000 elements). Figure 10(b) 
shows some of these contours. Figure 12 shows values of the J-integral which are obtained from FEM simulation of specimens $\mathrm{U} 1$ and $\mathrm{W} 1$. Due to the assumption of linear elastic behavior, this value is equal to the $G_{\mathrm{C}}$. As it can be seen, values of the fracture toughness of the specimens converge from second contour onwards.

Fig. 12

J-integral (is equal to $G_{\mathrm{C}}$ ) values in 8 contours obtained from FEM analyses for the specimens U1 and W1 (mode I)
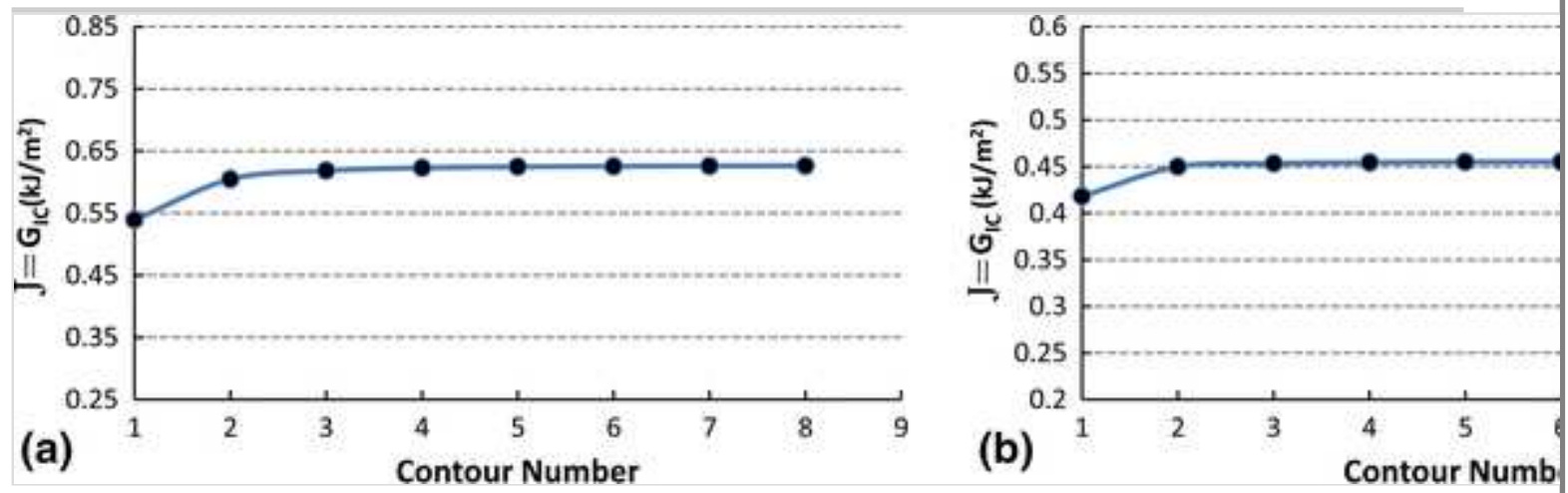

Table 4 shows the value of energy release rate obtained from finite element simulation for the specimens.

Table 4

The $G_{\mathrm{C}}$ values obtained from FEM analyses for the specimens

\begin{tabular}{|l|l|l|l|l|l|l|}
\hline Specimens & $\mathbf{U} 1$ & $\mathbf{W 1}$ & $\mathbf{U} 2$ & $\mathbf{W} 2$ & $\mathbf{U 3}$ & $\mathbf{W 3}$ \\
\hline$J=G_{\mathrm{C}}\left(\mathrm{kJ} / \mathrm{m}^{2}\right)$ & 0.62 & 0.46 & 0.23 & 0.11 & 1.970 & 0.370 \\
\hline
\end{tabular}

Figure 13(a) shows distribution of normal and shear stresses in specimen U1. As it is clear from Fig. 13(a), normal stress in the DCB specimens is high and shear stress in these specimens are negligible. Thus, the dominant failure mechanism in these specimens is fiber breakage and matrix cracking event is smaller than fiber breakage (Fig. 14a). According to Fig. 13(b), in ENF specimens shear stress is high and normal stress is small. Thus, the dominant failure mechanism is matrix cracking and fiber breakage percentage is small (Fig. 14b). Referring to Fig. 13(c), both normal and shear stresses are considerable in MMB specimens. Thus, these specimens contain combination of fiber 
breakage and matrix cracking failures (Fig. 14c). These results are due to the fact that fiber breakage event is dominant when there is fiber bridging and fibers stretching, which almost happen in normal stress condition. But matrix cracking may happen both in normal and shear stress condition.

\section{Fig. 13}

Normal and shear stresses distribution in: (a) mode I, (b) mode II, and (c) mixed-mode I and II loading condition
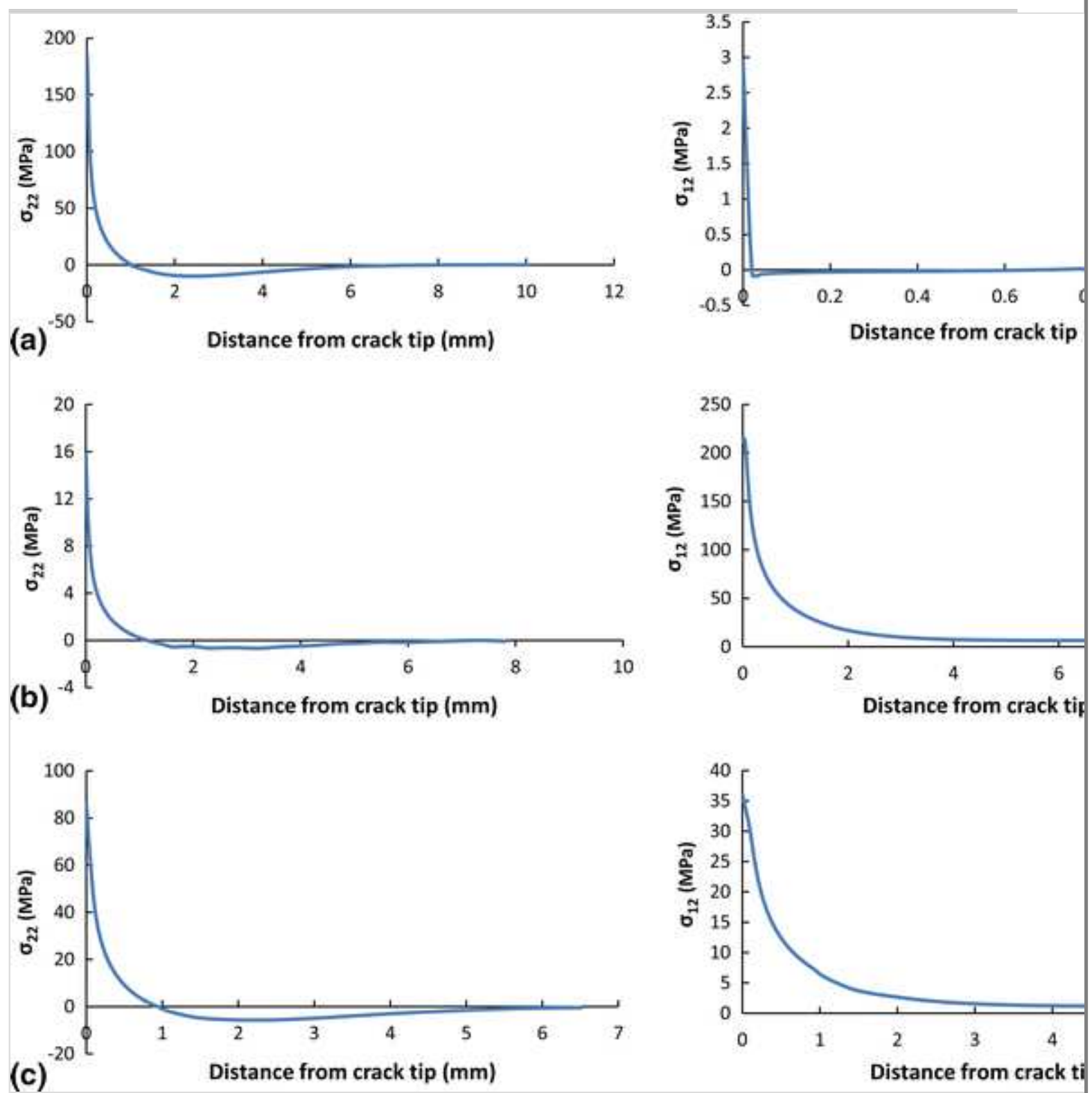

\section{Fig. 14}

SEM images of the damaged surfaces of the specimens under: (a) mode I, (b) mode II, and (c) mixed-mode I and II loading condition 
(a)

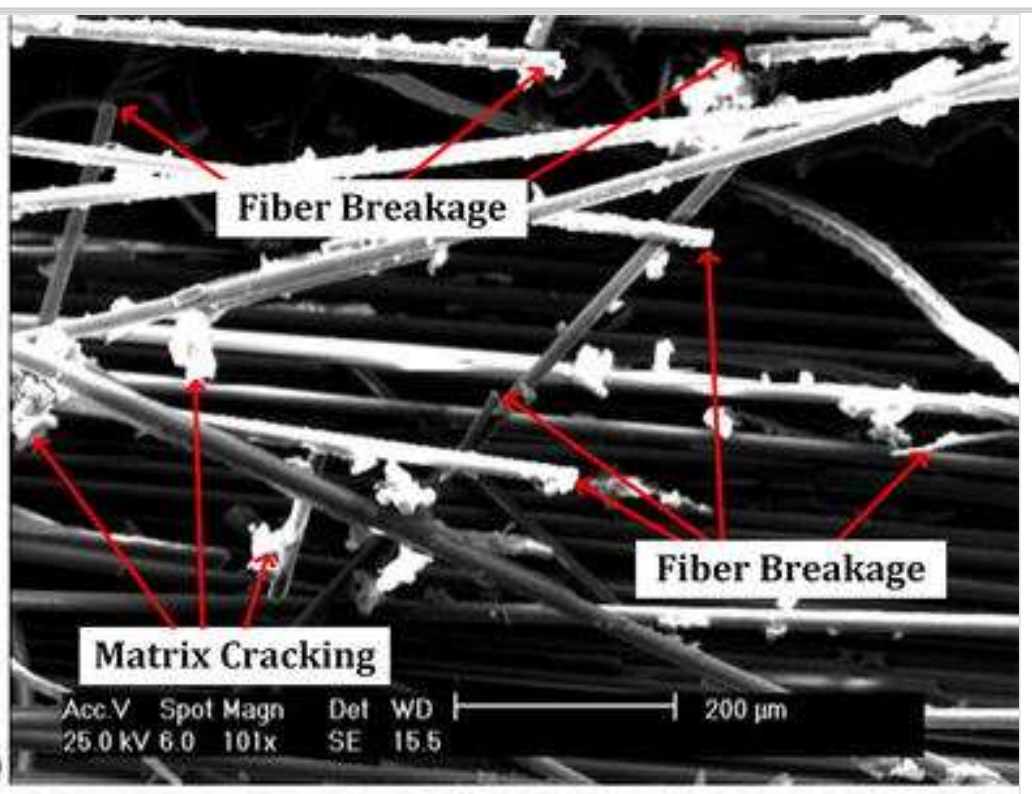

(b)
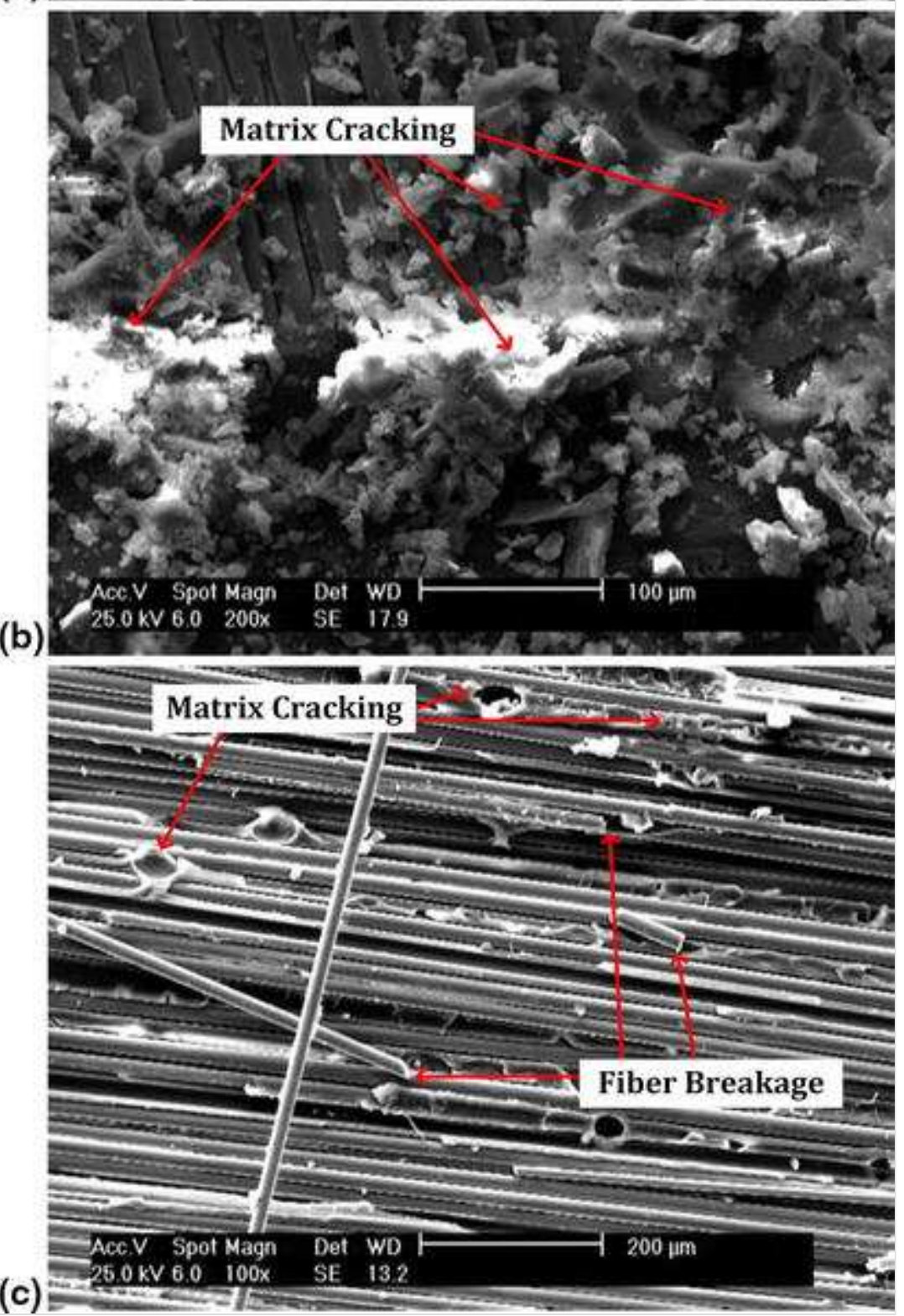

Acoustic Emission Method

http://eproofing.springer.com/journals/printpage.php?token=F0uNpJyzVSkLfuwMLz... $\quad$ 11/5/2014 
In analogy to the mechanical behavior of the specimens and existence of three regions in the load-displacement curves, similar trend in the acoustic emission behavior of the specimens is observed. These regions are illustrated for specimen U2 in Fig. 15. In region (a), no significant $\mathrm{AE}$ activity is observed. In region (b), by initiation of delamination the $\mathrm{AE}$ activities initiate and increase rapidly. In region (c), by activation of damage mechanisms and growth of delamination in the specimens, AE activities with medium energy are observed.

\section{Fig. 15}

The energy of AE signals, during the initiation and propagation of the delamination in specimen $\mathrm{U} 2$

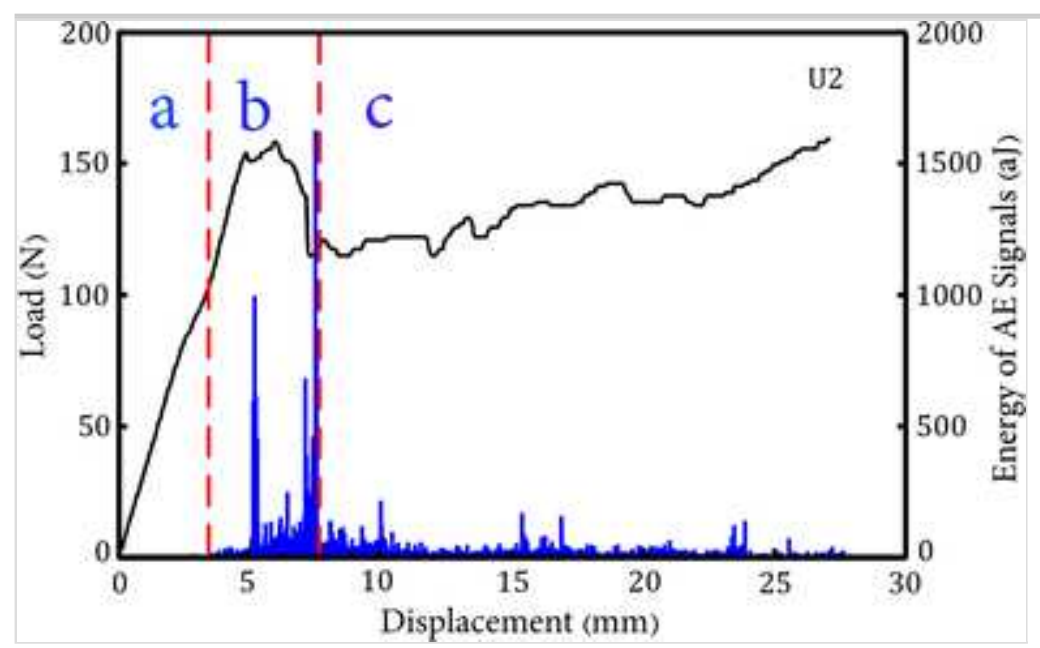

Similar to the mechanical method, the critical load value can be determined using the AE information. In this section, for identification of critical load two methods are used: (a) energy of AE signals and (b) cumulative energy of AE signals which is sum of the energy of the recorded AE signals. In the first method, the load at the point at which first surge in the energy of AE signals is observed, is equal to $P_{C}$. Figure 16 shows the critical load $\left(P_{\mathrm{C}}\right)$ obtained by this method for specimen W1.

Fig. 16

Determination of critical load value using AE energy approach for specimen $\mathrm{W} 1$ 


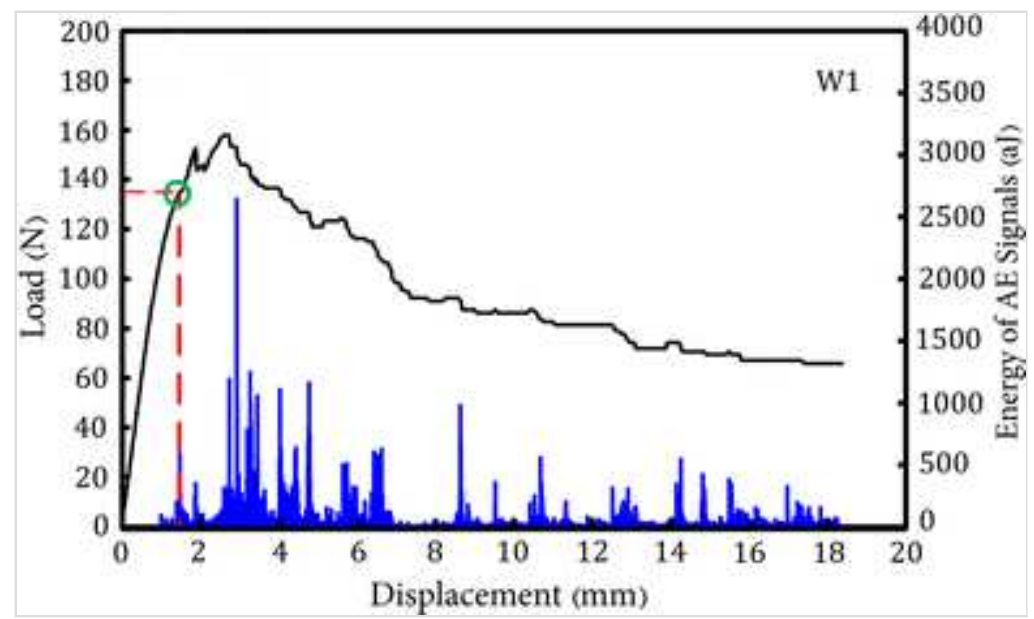

In the second method, the load at the point at which first surge in the cumulative energy of AE signal appears is equal to $P_{\mathrm{C}}$. Figure 17 shows the critical load $\left(P_{\mathrm{C}}\right)$ obtained by this method for specimen $\mathrm{U} 1$.

Fig. 17

Determination of critical load value using AE cumulative energy approach for specimen U1

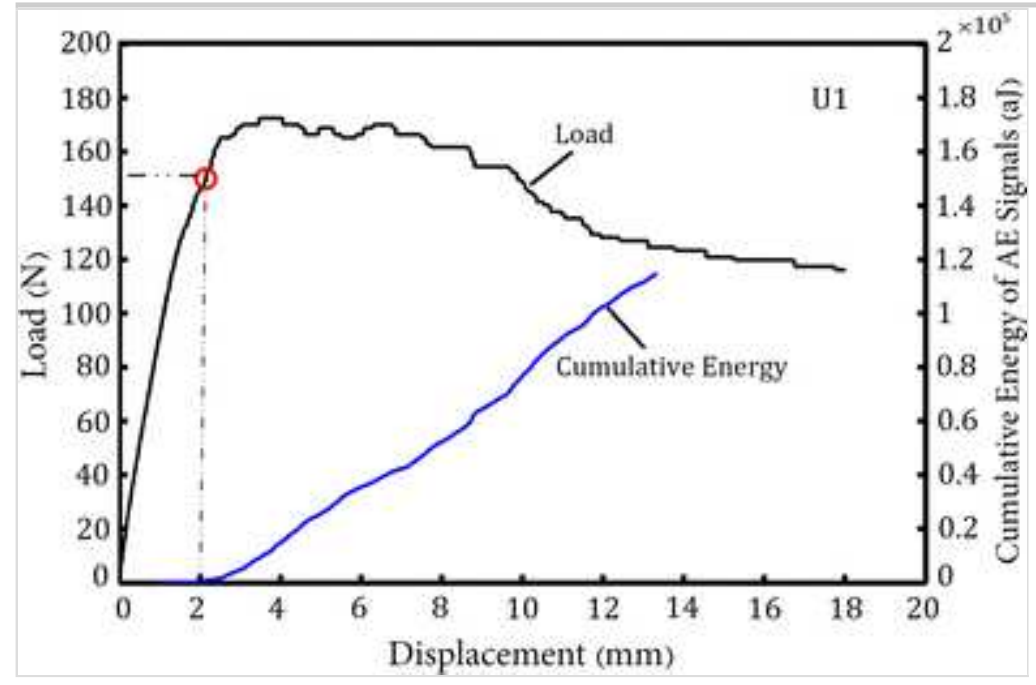

\section{Sentry Function}

In the previous sections, mechanical information and $\mathrm{AE}$ information were used separately for characterization of the damage. Combination of mechanical data and $\mathrm{AE}$ information can also be used to have comprehensive damage characterization in the specimens. The function which is used for this combination is called sentry function. As 
indicated by Eq 6, the sentry function is stated in the logarithm form of the ratio of mechanical energy to acoustical energy (Ref 26):

$$
f(x)=\operatorname{Ln}\left[\frac{E_{\mathrm{S}}(x)}{E_{\mathrm{a}}(x)}\right],
$$

where $E_{\mathrm{S}}(x), E_{\mathrm{a}}(x)$, and $x$ are the strain energy (mechanical energy), the $\mathrm{AE}$ events energy, and the displacement, respectively. For calculation of the two energies, two reference volumes were considered: the volume of the material where the strain energy is stored $\left(V_{1}\right)$ and the volume where the delamination can propagate $\left(V_{2}\right)$ and from which the $\mathrm{AE}$ events can occur. Thus, for calculation of sentry function, the strain energy was normalized over the $V_{1}+V_{2}$ volume and cumulative acoustic energy was normalized over the $V_{2}$ volume (Ref 16). Figure 18 shows the reference volumes in DCB specimen.

Fig. 18

The reference volumes in DCB specimen

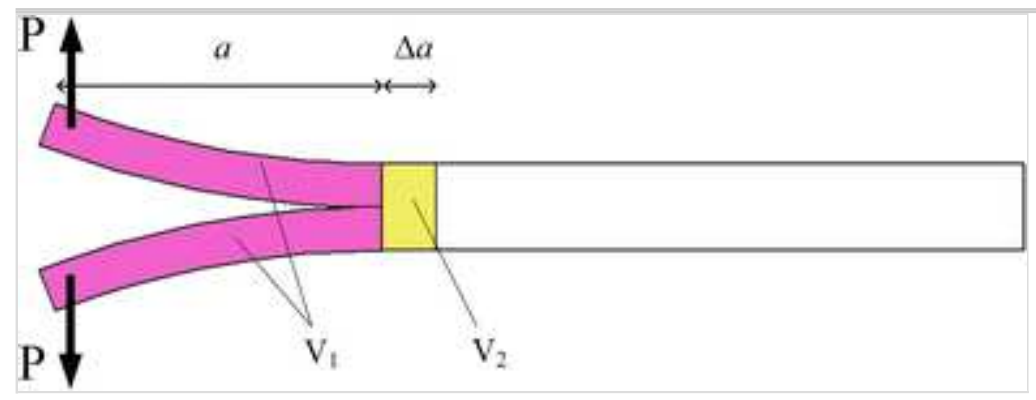

By applying load, there is an increasing trend in the stored strain energy in the specimens. The cumulative AE energy is also low before the initiation of delamination (free failure domain). Therefore, sentry function has increasing trend. As the applied load increases, progressively the ability of the material to store strain energy reaches its limits and the AE cumulative energy considerably increases as a result of micro-failures appearance. Therefore, the slope of the sentry function trend decreases. During the delamination progression major failures occur in the specimen and there is an instantaneous release of stored energy caused by internal material failure. This major failure is considered as a significant damage level in delamination and it is in accordance with the initiation of delamination. This is shown by the 
abrupt drop in the sentry function. The load at the point at which the sentry function decreases instantaneously, is equal to $P_{\mathrm{C}}$. Figure 19 shows identification of $\mathrm{P}_{\mathrm{C}}$ with sentry function method for specimen W1. Table 5 represents values of $G_{\mathrm{C}}$ are obtained by the AE energy, cumulative AE energy, and sentry function methods for the specimens.

Fig. 19

Determination of critical load value using sentry function approach for specimen $\mathrm{W} 1$

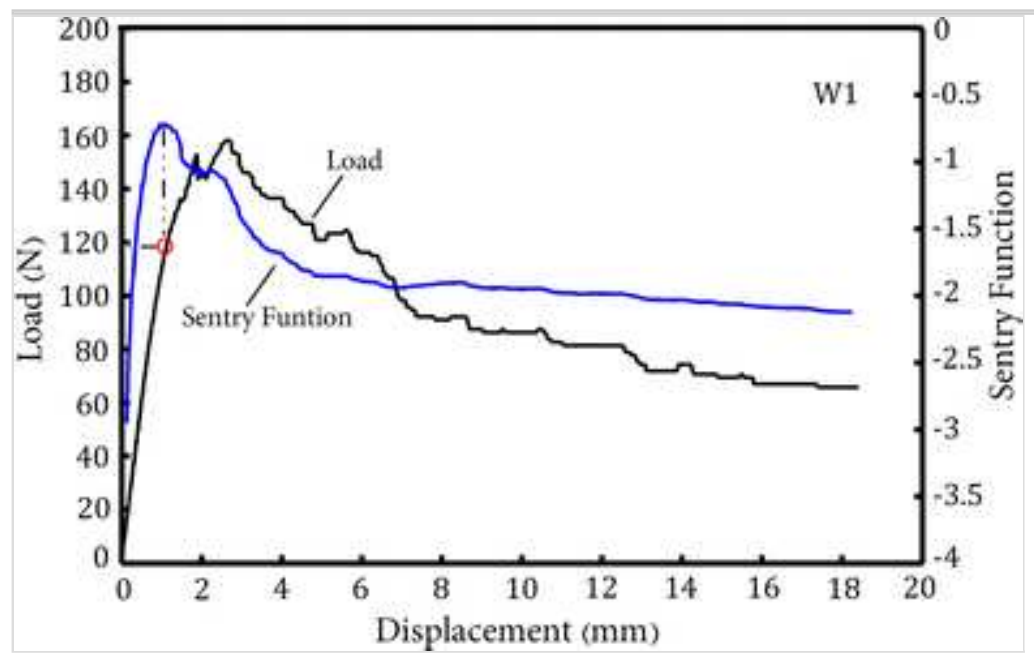

\section{Table 5}

The $G_{\mathrm{C}}$ values obtained from the $\mathrm{AE}$ energy, cumulative $\mathrm{AE}$ energy, and sentry function methods for the specimens

\begin{tabular}{|l|l|l|l|l|l|l|}
\hline \multirow{2}{*}{ Approaches } & \multicolumn{3}{|l}{$G_{\mathrm{C}}\left(\mathbf{k J} / \mathbf{m}^{2}\right)$} \\
\cline { 2 - 7 } & $\mathbf{U 1}$ & $\mathbf{W 1}$ & $\mathbf{U 2}$ & $\mathbf{W 2}$ & $\mathbf{U 3}$ & $\mathbf{W 3}$ \\
\hline AE (energy) & 0.42 & 0.50 & 0.46 & 0.13 & 2.01 & 0.46 \\
\hline AE(cumulative energy) & 0.83 & 0.466 & 0.29 & 0.13 & 2.06 & 0.435 \\
\hline Sentry function & 0.404 & 0.39 & 0.254 & 0.10 & 1.81 & 0.32 \\
\hline
\end{tabular}

Figure 20 shows values of interlaminar fracture toughness of the specimens which are obtained by the offered methods. NL method provides the most conservative value among 5\% increase in compliance and VIS methods and is recommended by ASTM standard (Ref 21, 22). The sentry function method and FEM analysis give the lower bound of 
the $G_{\mathrm{C}}$ values and are most consistent with the results obtained from NL method. The values obtained from AE methods are between the lower and upper bound values. Since the sentry function related to mechanical and $\mathrm{AE}$ events in the specimens, it has additional sensitivity to the occurrence of damages in the specimens and has more repeatability compared to the other methods. Due to VIS method dependences to the camera resolution and operator skill, this method has low repeatability and gives upper bound of the $G_{\mathrm{C}}$ values. Inter-laboratory variations, operator-dependent variations and dependency on delamination behavior (stable or unstable) are some disadvantages of VIS method. Also, due to different crack tip conditions and various distributions of stress components in the crack tip of the specimens, values of the $G_{\mathrm{C}}$ in the specimens under different loading conditions are varied.

Fig. 20

The values of the $G_{\mathrm{C}}$ for the specimens which are obtained from the offered methods

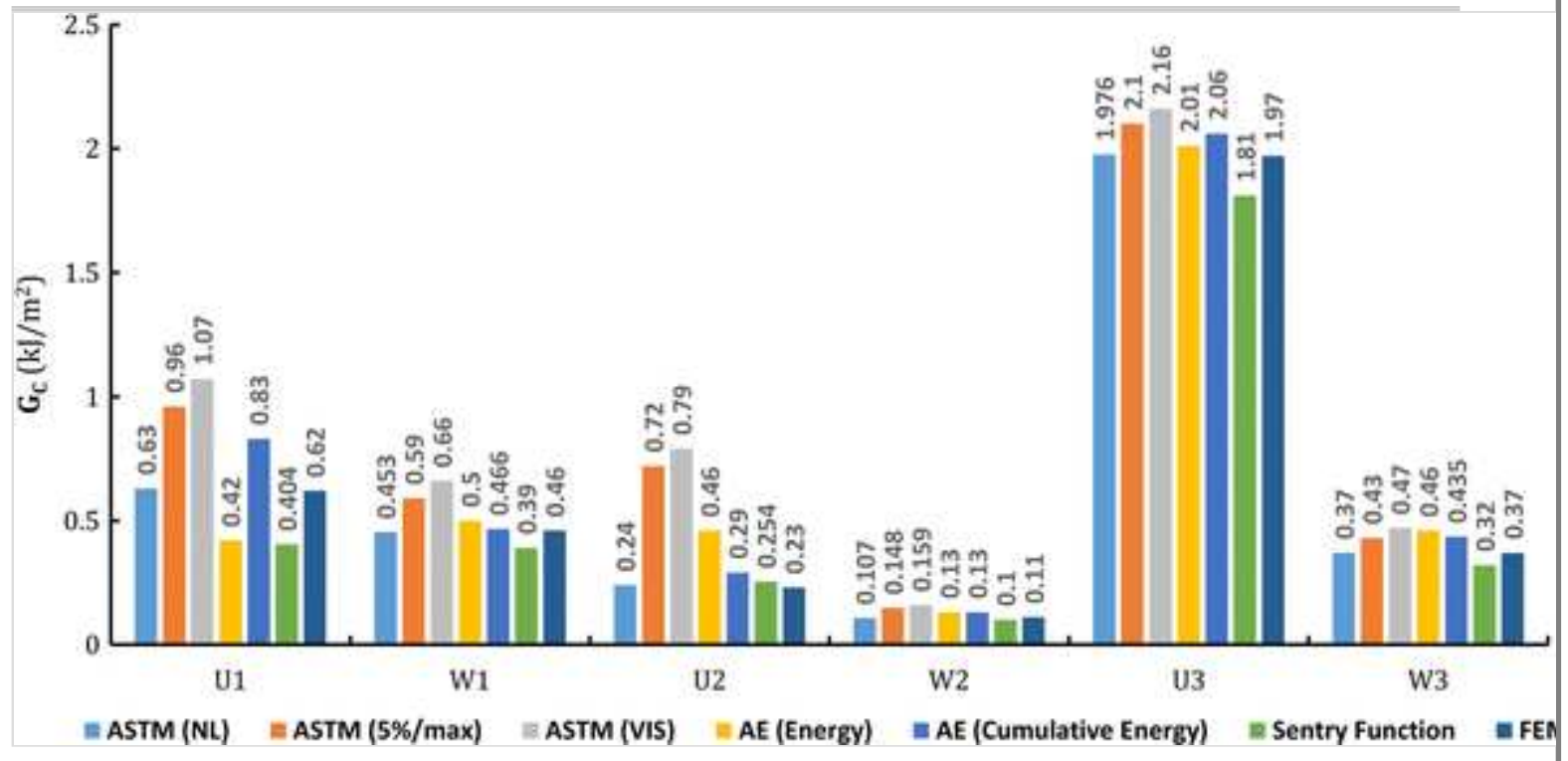

\section{Conclusion}

This study focused on investigation of delamination in laminated composite materials and the following conclusions may be drawn:

(a) It was found that methods based on mechanical data and AE information are powerful procedures to characterize the initiation and propagation of the delamination in the glass/epoxy specimens 
under mode I (DCB), mode II (ENF), and mixed-mode I and II (MMB) loading conditions.

(b) The developed methods for evaluation of interlaminar fracture toughness for initiation of delamination, $G_{\mathrm{C}}$, lead to the results which are in excellent agreement with the obtained results from ASTM standard methods and can solve their weaknesses, especially in mode II and mixed-mode conditions, where unstable crack growth and closed crack tip during delamination propagation preclude a rigorous measurement of $G_{\mathrm{C}}$. In addition, these methods are easier and have higher repeatability compared with previous methods.

(c) The results obtained from FEM analysis and AE method, especially sentry function method, are shown to be more conservative than those derived from conventional fracture mechanics methodologies. This is due to the fact that $\mathrm{AE}$ monitoring is able to detect micro-damage mechanisms that occur before delamination is observed.

(d) It was also found that $G_{\mathrm{II}} / G_{\mathrm{T}}$ modal ratio value and interface layup types cause different crack tip stress contributions and cause different damage mechanisms such as fiber breakage and matrix cracking during loading process. These fracture mechanisms are sources of the variation of mechanical information, AE parameters, and interlaminar fracture toughness values. FEM results and SEM observation also used to evaluate appeared damage mechanisms. Finally, it is concluded that AE examination is a powerful method for post-test and on-line analysis of delamination characteristics with less operator-dependent variations.

\section{Acknowledgment}

The authors wish to thank the Department of Mechanical Engineering at Amirkabir University of Technology, for providing the facilities for this study. 


\section{References}

1. S. Sridharan, Delamination Behaviour of Composites, CRC Press, New York, 2008

2. A.A. Bakhtiary Davijani, M. Hajikhani, and M. Ahmadi, Acoustic Emission Based on Sentry Function to Monitor the Initiation of Delamination in Composite Materials, Mater. Des., 2011, 32, p 3059 $-3065$

3. A.B. de Morais, A.B. Pereira, M.F.S.F. de Moura, and A.G. Magalhães, Mode III, Interlaminar Fracture of Carbon/Epoxy Laminates Using the Edge Crack Torsion (ECT) Test, Compos. Sci. Technol., 2009, 69(5), p 670-676

4. I. Ndiaye, A. Maslouhi, and J. Denault, Characterization of Interfacial Properties of Composite Materials by Acoustic Emission, Polym. Compos., 2000, 21, p 595-604

5. J. Bohse and A.J. Brunner, Acoustic Emission in Delamination Investigation, Delamination Behaviour of Composites, S. Sridharan, Ed., CRC Press, New York, 2008, p 217-277

6. G. Minak and A. Zucchelli, Damage Evaluation and Residual Strength Prediction of CFRP Laminates by Means of Acoustic Emission Techniques, Composite Materials Research Progress, L.P. Durand, Ed., Nova Science Publishers Inc, New York, 2008, p 165207

7. R. de Oliveira and A.T. Marques, Health Monitoring of FRP Using Acoustic Emission and Artificial Neural Networks, Comput. Struct., 2008, 86, p 367-373

8. S. Huguet, N. Godin, R. Gaertner, L. Salmon, and D. Villard, Use of Acoustic Emission to Identify Damage Modes in Glass Fibre Reinforced Polyester, Compos. Sci. Technol., 2002, 62(10-11), p 1433-1444 
9. F. Pashmforoush, M. Fotouhi, and M. Ahmadi, Acoustic Emission -Based Damage Classification of Glass/Polyester Composites Using Harmony Search k-means Algorithm, J. Reinf. Plast. Compos., 2012, 31, p 671-680

10. M. Fotouhi, H. Heidary, M. Ahmadi, and F. Pashmforoush, Characterization of Composite Materials Damage Under Quasi-static Three-point Bending Test Using Wavelet and Fuzzy C-means Clustering, J. Compos. Mater., 2012, 46(15), p 1795-1808

11. I.A. Ashcroft, D.J. Hughes, and S.J. Shaw, Mode I, Fracture of Epoxy Bonded Composite Joints: 1. Quasi-static Loading, Int. J. Adhes. Adhes., 2001, 21(2), p 87-99

12. A.B. de Morais, M.F. de Moura, A.T. Marques, and P.T. de Castro, Mode-I, Interlaminar Fracture of Carbon/Epoxy Cross-ply Composites, Compos. Sci. Technol., 2002, 62(5), p 679-686

13. F. Perrin, M.N. Bureau, J. Denault, and J.I. Dickson, Mode I, Interlaminar Crack Propagation in Continuous Glass

Fiber/Polypropylene Composites: Temperature and Molding Condition Dependence, Compos. Sci. Technol, 2003, 63(5), p 597607

14. S. Benmedakhene, M. Kenane, and M.L. Benzeggagh, Initiation and Growth of Delamination in Glass/Epoxy Composites Subjected to Static and Dynamic Loading by Acoustic Emission Monitoring, Compos. Sci. Technol., 1999, 59, p 201-208

15. M. Fotouhi and M. Ahmadi, Acoustic Emission-Based Study to Characterize the Initiation of Delamination in Composite Materials, J. Thermoplast. Compos. Mater., 2014, doi:10.1177/0892705713519811

16. A. Refahi Oskouei, A. Zucchelli, M. Ahmadi, and G. Minak, An Integrated Approach Based on Acoustic Emission and Mechanical Information to Evaluate the Delamination Fracture Toughness at 
Mode I, in Composite Laminate, Mater. Des., 2011, 32(3), p 14441455

17. V. Arumugam, S. Sajith, and A. Joseph, Stanley, Acoustic Emission Characterization of Failure Modes in GFRP Laminates Under Mode I, Delamination, J. Nondestr. Eval., 2011, 30(3), p 213219

18. J. Taghizadeh and M. Ahmadi, Identification of Damage Modes In Polypropylene/Epoxy Composites by Using Principal Component Analysis on AE Signals Extracted from Mode I, Delamination, Nondestruct. Test. Eva., 2012, 27(2), p 151-170

19. F. Pashmforoush, M. Fotouhi, and M. Ahmadi, Damage Characterization of Glass/Epoxy Composite Under Three-Point Bending Test Using Acoustic Emission Technique, J. Mater. Eng. Perform., 2012, 21, p 1380-1390

20. J. Yousefi, M. Ahmadi, M. Nazmdar, A. Refahi, and F. Moghadas, Damage Categorization of Glass/Epoxy Composite Material under Mode II, Delamination Using Acoustic Emission Data: A Clustering Approach to Elucidate Wavelet Transformation Analysis, Arab. J. Sci. Eng., 2013, 39, p 1325-1335

21. ASTM D5528-01, Standard Test Method for Mode I Interlaminar Fracture Toughness of Unidirectional Fiber-Reinforced Polymer Matrix Composites, 2007.

22. ASTM D 6671/D 6671M-03, Standard Test Method for Mixed Mode I-Mode II Interlaminar Fracture Toughness of Unidirectional Fiber Reinforced Polymer Matrix Composites, 2004.

23. T.L. Anderson, Fracture Mechanics; Fundamentals and Applications, Taylor \& Francis, Boca Raton, 2005, p 43-110

24. I. Paris and A. Poursartip, Delamination Crack Tip Behavior at Failure in Composite Laminate Under Mode I, Loadings, $J$. Thermoplast. Compos. Mater., 1998, 11, p 57-69 
25. M.G. Andrews, R. Massabò, and B.N. Cox, Elastic Interaction of Multiple Delaminations in Plates Subject to Cylindrical Bending, Int. J. Solids Struct., 2006, 43(5), p 855-886

26. G. Minak, P. Morelli, and A. Zucchelli, Fatigue Residual Strength of Circular Laminate Graphite-Epoxy Composite Plates Damaged by Transverse Load, Compos. Sci. Technol., 2009, 69(9), p $1358-1363$ 